\title{
The relaxant effect of methanolic extract of yohimbe bark (Pausinystalia yohimbe) on rabbit corpus cavernosum smooth muscles
}

\author{
Mohamed Hassan Hozeifa ${ }^{1^{*}}, I_{\operatorname{mad}}$ Eldin Mohamed Taj Eldin ${ }^{1}$, \\ Mohamed Mohamed Ahmed Elhadi ${ }^{2}$, Hassan Mohamed Abd Elwahab ${ }^{3}$, Sirag Elteyb Nizar ${ }^{2}$ \\ ${ }^{1}$ Department of Pharmacology, Faculty of Pharmacy, University of Gezira, Wad Madani, Sudan; \\ *Corresponding Author: hozhooz@hotmail.com \\ ${ }^{2}$ Department of Pharmacognosy, Faculty of Pharmacy, University of Gezira, Wad Madani, Sudan \\ ${ }^{3}$ Department of Pharmacology and Toxicology, Medicinal and Aromatic Plant Research Institute, National Center for Research, \\ Khartoum, Sudan
}

Received 26 June 2012; revised 25 July 2012; accepted 12 August 2012

\begin{abstract}
Background: Development and maintenance of penile erection requires the relaxation of corpus cavernosum smooth muscle (CCSM) cells and it is essentially mediated by nitric oxide (NO). Pausinystalia yohimbe bark is traditionally used for the treatment of erectile dysfunction (ED). Objectives and Methods: This study aimed to evaluate the effects of the methanolic extract of $P$. yohimbe bark $(10 \mathrm{mg} / \mathrm{ml})$ on isolated rabbit corpus cavernosum smooth muscle (CCSM). Results: Methanolic extract of $P$. yohimbe bark blocked contractions in CCSM induced by adrenergic agonists, through facilitating NO release from the endothelial cells. Conclusion: The obtained results revealed that, methanolic extract of $P$. yohimbe bark caused relaxation of CCSM that validates its traditional aphrodisiac property, thus it could be used to initiate and maintain erection in cases of erectile dysfunction.
\end{abstract}

Keywords: P. yohimbe Bark; Corpus Cavernosum Relaxation; Nitric Oxide; Aphrodisiac; Erectile Dysfunction

\section{INTRODUCTION}

Disorders of sexual function are common among men of all ages, ethnicities and cultural backgrounds [1]. Sexual function is considered as an interaction among motivation, drive, desires, thoughts, fantasies, pleasures, experiences (libido), penile vasocongestion, erection, orgasmic contractions and ejaculations (potency) [2].

Sexual dysfunction can be categorized into three main phases of response: desire; arousal-priapism and impo- tence (erectile dysfunction, ED) [3]. In 1995, it has been estimated that more than 152 million men worldwide experienced erectile dysfunction, and this number will rise by 170 million, to approximately 322 million by the year 2025 [1].

Significant advances in the understanding of the physiology and pathophysiology of male ED, and in methods of its investigation and treatment, have been attained during the past three decades. ED has both organic and psychogenic etiologies. About $60 \%$ of patients have organic ED, which can be define in terms of vasculogenic, neurological, hormonal, or smooth muscle abnormalities. In the same instance approximately $<40 \%$ of the patients have truly psychogenic ED. In fact, some cases may be labeled as psychogenic simply because organic cause is not yet identified. Some patients with psychogenic causes, specifically stress disorders and depression, have an overactivity of alpha-agonists in their corpus cavernosum smooth muscle tissue, so a chemical imbalance may be to blame [4].

Therapies for ED may include psychosexual counseling, androgen replacement therapy, vacuum constriction device, surgical treatment and most commonly the orally administered agents like sildenafil and tadalafil; specific phosphodiesterase type 5 (PDE5) inhibitors and alprostadil [5].

Traditionally, herbs may be a potential source of natural drugs for therapy against ED. Plants that belong to the family Apocyanaceae are known to be rich in indole alkaloids and have an ethnomedical history of use as remedies for ED [6,7].

Yohimbine is the principal indole alkaloid in the bark of the West-African tree Pausinystalia yohimbe Pierre ex Beille (formerly Corynanthe yohimbe) family Rubiaceae. The bark of the tree is traditionally used in Africa and 
West Indian medicine as an aphrodisiac with the ability to increase sexual potency and virility $[8,9]$. It is possible that the positive effect of yohimbine on penile erection is not only related to its central effect but also to a peripheral sympatholytic activity [10].

This study aimed to evaluate the effects of the methanolic extract of Pausinystalia yohimbe bark on isolated rabbit corpus cavernosum smooth muscles. The experimental protocol was ethically approved by the ethical committee at Faculty of Pharmacy, University of Gezira.

\section{MATERIALS AND METHODS}

\subsection{Plant Material}

The dried chopped small pieces of $P$. yohimbe barks had been collected from South West Cameroon in May 25th, 2008. The plant material was authenticated by the Provincial Service for Forestry, Ministry of Forestry and Wildlife, Republic of Cameroon (Certificate No. 004/ CO/MINFOF/PDFOF/PSF/SW/230).

\subsection{Extraction of Plant Material}

The coarsely powdered barks (500 grams) of $P$. yohimbe were extracted by maceration using pure methanol in a conical flask for 72 hours with intermittent shaking, filtered and evaporated by rotary evaporator at $60^{\circ} \mathrm{C}$. The dried extract powder was kept in an amber glass container in a refrigerator for the biological test.

\subsection{The Effect of Methanolic Extract of $P$. yohimbe Barks on Rabbit Corpus Cavernosum Smooth Muscle (CCSM) Preparation}

This experiment was carried out according to the method described by Allex, et al., 1998 [11]. In this method, a sexually mature male New Zealand white rabbit weighing $6.5 \mathrm{~kg}$ was chosen. The animal was killed by neck dislocation and the penis was removed immediately, placed in a petri dish containing oxygenated ice cold Krebs solution $\left(4^{\circ} \mathrm{C}\right)$ and the corpus cavernosum smooth muscle (CCSM) was carefully dissected free from the enveloping tunica albuginea and cut into three strips. Threads were attached at each end of the CCSM strip, and then mounted in a $25 \mathrm{ml}$ water-jacketed tissue bath containing Krebs solution maintained at $37^{\circ} \mathrm{C}$ and supplied continuously with oxygen. The tissue was allowed to equilibrate for 45 minutes, under $1.5 \mathrm{~g}$ resting tension. Conventional drugs such as phenylephrine (25 $\mu \mathrm{g} / \mathrm{ml})$, adrenaline $(1 \mathrm{mg} / \mathrm{ml})$, and sildenafil $(3.2 \mathrm{mg} / \mathrm{ml})$ were initially tested isometrically using CCSM strip [12] followed by the methanolic extract of $P$. yohimbe bark (10 mg/ml).

\section{RESULTS}

Methanolic extract of Pausinystalia yohimbe bark (10 $\mathrm{mg} / \mathrm{ml}$ ) alone reduced the basal tone in unstimulated CCSM. The exposure of rabbit corpus cavernosum preparation to $\alpha_{1}$-adrenoceptor agonists, phenylephrine (25 $\mu \mathrm{g} / \mathrm{ml})$ and adrenaline $(1 \mathrm{mg} / \mathrm{ml})$ resulted in little and apparent isometric contractile tension responses respectively.

When sildenafil citrate $(3.2 \mathrm{mg} / \mathrm{ml})$ was tested using adrenaline precontracted corpus cavernosum, an obvious and fast relaxation was produced (Figure 1). The methanolic extract of $P$. yohimbe bark $(10 \mathrm{mg} / \mathrm{ml})$ completely relaxed adrenaline precontracted rabbit CCSM (Figure 2) in the same manner as sildenafil. This relaxant effect of the methanolic extract of $P$. yohimbe bark is not surprising because yohimbine is a well known $\alpha_{1}$-adrenoceptor antagonist. In line with this, methanolic extract of $P$. yohimbe bark may cause relaxation of the precontracted corporal cavernosal tissue through inhibition of the phosphodiesterase type 5 (PDE-5), an enzyme which is predominantly expressed in the smooth muscle of the

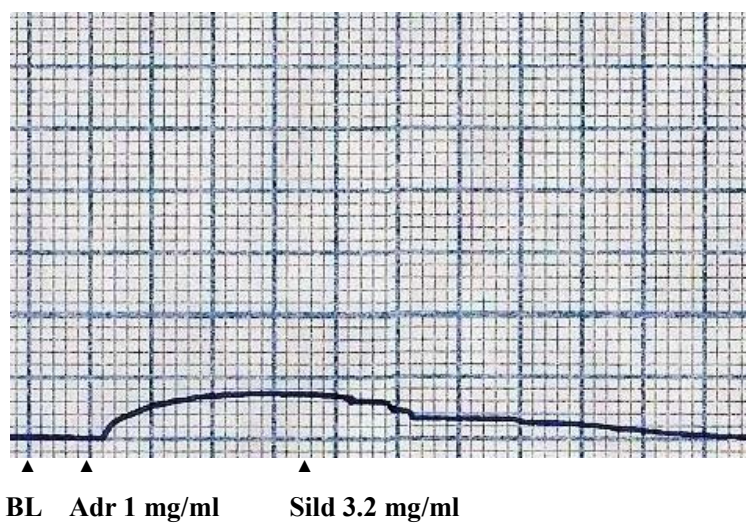

Figure 1. Actions of adrenaline (Adr) and sildenafil (Sild) on isolated rabbit corpus cavernosum smooth muscles, (BL) baseline.

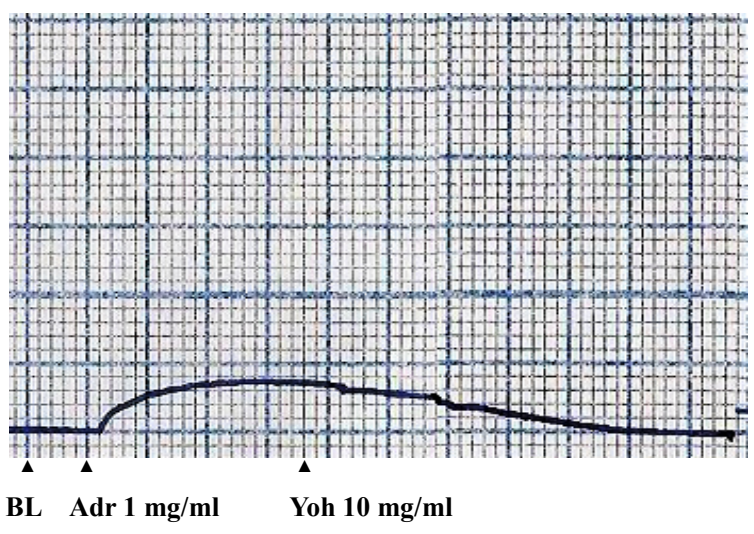

Figure 2. Actions of adrenaline (Adr) and P. yohimbe extract (Yoh) on isolated rabbit corpus cavernosum smooth muscles, (BL) baseline. 
corpus cavernosum [12-14].

In order to test whether or not the relaxation induced by methanolic extract of $P$. yohimbe bark was due to NO production, another experiment was carried out using aortic strip in the presence of methylene blue, a reversible NO inhibitor (a soluble guanylyl cyclase inhibitor). The $P$. yohimbe extract $(5 \mathrm{mg} / \mathrm{ml})$ relaxed the contracted aortic strip to the normal base line with maximal relaxation activity occurred after 1 minute. This relaxant effect of the extract was blocked by the pre-addition of methylene blue $(25 \mu \mathrm{g} / \mathrm{ml})$.

\section{DISCUSSION}

Penile erection is a physiological event controlled by two opposite drives $[15,16]$. The first drive determines smooth muscle relaxation and an increase in cavernosal blood flow. The activity of this system is essentially mediated by the parasympathetic nitergic network. The second drive, operating for the majority of time, determines smooth muscle contraction and it is controlled by the sympathetic outflow [17].

Development and maintenance of penile erection requires the relaxation of the smooth muscle cells in the cavernous bodies and is essentially mediated by NO $[18,19]$. Sildenafil is known to cause relaxation of the precontracted corporal tissue through inhibition of the phosphodiesterase type 5 (PDE-5) an enzyme which is predominantly expressed in the smooth muscle of the corpus cavernosum. This enzyme hydrolyzes cyclic guanosine monophosphate (cGMP), which is the intracellular mediator of the NO signaling pathway. Nitric oxide causes relaxation of the smooth muscle, enabling the vasodilatation that is necessary for erection to occur. Inhibition of PDE-5 prevents the breakdown of cGMP, permitting the biological cascade of events that is required for normal erectile function [12-14].

The addition of the methanolic extract of $P$ yohimbe bark resulted in relaxation of the precontracted tissue; this relaxation effect perhaps due to release of NO from the endothelial cells of the corpus cavernosum smooth muscle rather than adrenergic receptors blocking activity. This is because; methanolic extract of $P$. yohimbe bark failed to produce relaxation in the precontracted isolated aortic strip smooth muscles in the presence of methylene blue, a NO synthesis inhibitor.

These results demonstrated the dominant NO network involvement in corpora cavernosa relaxation obtained. These findings were supported by pervious sophisticated results which concerned with examination of yohimbine-induced relaxation in human and rabbit corpora cavernosa through interfering with NO release from the endothelium. The yohimbine-induced corpus cavernosum relaxation was inhibited by mechanical removal of the endothelium and by blocking NO formation or sig- naling via guanylate cyclase and cGMP formation [2028].

Yohimbine was found to be beneficial and effective in treatment of psychogenic and/or organic erectile dysfunction when taken in divided daily doses [21-25].

It can be concluded that, $P$. yohimbe methanolic extract causes relaxation of the corpus cavernosum muscles, thus it could be used to initiate and maintain erection in cases of erectile dysfunction

\section{REFERENCES}

[1] Kandeel, R.F., Koussa, V.K.T. and Swerdloff, R.S. (2001) Male sexual function and its disorders: Physiology, pathophysiology, clinical investigation and treatment. Endocrine Reviews, 22, 342-388. doi:10.1210/er.22.3.342

[2] Koda-Kimble, M.A., Lloyd, Y.Y., Alldredge, B.K., Corelli, R.L., Guglielmo, J.B., Kradjan, W.A. and Williams, B.R. (2009) Applied therapeutics: The clinical use of drugs. 9th Edition, Lippincott Williams \& Wilkins, Philadelphia.

[3] Fecik, S.E. (1998) Drug-induced sexual dysfunction. Medical Update for Psychiatrists, 3, 176-181. doi:10.1016/S1082-7579(98)00024-7

[4] Carson, C.C. (2000). Erectile dysfunction: Diagnosis and management with newer oral agents. Baylor University Medical Center Proceedings, 13, 356-360.

[5] Matfin, G. (2003) New treatments for erectile dysfunction. Sexuality, Reproductive and Menopause, 1, 40-45. doi:10.1016/j.sram.2004.02.023

[6] Drewes, E.S., Jacob, G. and Fatima, K. (2003) Recent finding on natural products with erectile-dysfunction activity. Phytochemistry, 62, 1019-1025. doi:10.1016/S0031-9422(02)00621-0

[7] Khosravi, M., Oryan, S., Rohani, S.A.H., Parivar, K. and Marandi, R. (2006) Control of environmental health and removal of rats by $\alpha_{2}$-adrenergic antagonists and potassium channel blocker. Iranian Journal of Environmental Health Science and Engineering, 3, 255-260.

[8] Brunton, L., Keith, P., Donald, B. and Iain, B. (2008) Goodman and Gilman's manual of pharmacology and therapeutics. 11th Edition, McGraw-Hill Medical Publishing Division, New York.

[9] Zanolari, B. (2003) Natural aphrodisiacs. Studies of commercially-available herbal recipes, and phytochemical investigation of Erythroxylum vacciniifolium Mart. (Erythroxylaceae) from Brazil. PhD Thesis, University of Lausanne, Lausanne.

[10] De Tejada, I.S. et al. (1999) Design and evaluation of nitrosylated $\alpha$-adrenergic receptor antagonists as potential agents for the treatment of impotence. Journal of Pharmacology and Experimental Therapeutics, 290, 121-128.

[11] Allex, T.C., John, D.S., Richard, A.M. and William, D.S. (1998) Sildenafil, a type-5 cGMP phosphodiesterase inhibitor, specifically amplifies endogenous cGMP-dependent relaxation in rabbit corpus cavernosum smooth muscle in vitro. Journal of Urology, 160, 257-261. doi:10.1016/S0022-5347(01)63100-8 
[12] Siddig, I.A. (2001) Some pharmacological properties of the sudanese plant Clerodendorn capitatum. M.Sc. Thesis, University of Khartoum, Khartoum.

[13] Boolell, M., Allen, M.J., Ballard, S.A., Gepi-Attee, S., Muirhead, G.J. and Naylor, A.M. (1996). Sildenafil: An orally active type 5 cyclic GMP-specific phosphodiesterase inhibitor for the treatment of penile erectile dysfunction. International Journal of Impotence Research, $\mathbf{8}$, 47.

[14] Ballard, S.A. (1998) Effects of sildenafil on the relaxation of human corpus cavernosum tissue in vitro and on the activities of cyclic nucleotide phosphodiesterase isozymes. Journal of Urology, 159, 2165-2171. doi:10.1016/S0022-5347(01)63299-3

[15] Andersson, K.E. and Wagner, G. (1995) Physiology of penile erection. Pharmacology Review, 75, 191-236.

[16] Maggi, M. et al. (2000) Erectile dysfunction: From biochemical pharmacology to advances in medical therapy. European Journal of Endocrinology, 143, 143-154. doi:10.1530/eje.0.1430143

[17] Ignarro, L.J., et al. (1990) Nitric oxide and cyclic GMP formation upon electrical field stimulation cause relaxation of corpus cavernosum smooth muscle. Biochemical and Biophysical Research Communications, 170, 843-850. doi:10.1016/0006-291X(90)92168-Y

[18] Eardley, I. (2002) Pathophysiology of erectile dysfunction. The British Journal of Diabetes and Vascular Disease, 2, 272-276. doi:10.1177/14746514020020040701

[19] Dean, C.R. and Lue, F.T. (2005) Physiology of penile erection and pathophysiology of erectile dysfunction. Urologic Clinics of North America, 32, 379-402. doi:10.1016/j.ucl.2005.08.007

[20] Filippi, S., Luconi, M., Granchi, S., Natali, A., Tozzi, P., Forti, G., Ledda F. and Maggi, M. (2002) Endothelium dependency of yohimbine-induced corpus cavernosum relaxation. International Journal of Impotence Research, 14, 295-307. doi:10.1038/sj.ijir.3900890
[21] Ernst, E. and Pittler, M.H. (1998) Yohimbine for erectile dysfunction: A systematic review and meta-analysis of randomized clinical trials. Journal of Urology, 159, 433436. doi:10.1016/S0022-5347(01)63942-9

[22] Cary, P.M. and Johnson, T.B. (1996) Effectiveness of yohimbine in the treatment of erectile disorder: Four meta-analytic integrations. Archive of Sexual behavior, 25, 341-360

[23] Teloken, C., Rhoden, E.L., Sogari, P., Dambros, M. and Vargas Souto, C.A. (1998) Therapeutic effects of high dose yohimbine hydrochloride on organic erectile dysfunction. The Journal of Urology, 159, 122-124. doi:10.1016/S0022-5347(01)64032-1

[24] Vogt, H.J., Brand, P., Kockoh, G., Schmitz, J.R. Wiegand, M.H., Schadrack, J. and Gierend, M. (1997) Double-blind, placebo-controlled safety and efficacy trial with yohimbine hydrochloride in the treatment of non-organic erectile dysfunction. International Journal of Impotence Research, 9, 155-161. doi:10.1038/sj.ijir.3900271

[25] Reid, K., Surrivge, D.H., Morales, A., Condra, M., Harris, C., Owen, J. and Fenemore, J. (1987) Double-blind trial of yohimbine in treatment of psychogenic impotence. Lancet, 2, 421-423. doi:10.1016/S0140-6736(87)90958-5

[26] Mann, K., Klingler, T., Noe, S., Roschke, J., Muller, S. and Benkert, O. (1996) Effect of yohimbine on sexual experiences and nocturnal penile tumescence and rigidity in erectile dysfunction. Archives of Sexual Behavior, 25, 1-16. doi:10.1007/BF02437904

[27] Rowland, D.L., Kallan, K. and Slob, A.K. (1997) Yohimbine, erectile capacity and sexual response in men. Archives of Sexual Behavior, 26, 49-62. doi:10.1023/A:1024521403389

[28] Guay, A.T., Spark, R.F., Jacobson, J., Murray, F.T. and Geisser, M.E. (2002) Yohimbine treatment of organic erectile dysfunction in a dose-escalation trial. International Journal of Impotence Research, 14, 25-31. doi:10.1038/sj.ijir.3900803 